\title{
Polymerization in Magnetic Field. XX. Thermal Behavior of the Copoly- mers of Styrene with 2, 3 Epoxypropyl Methacrylate Synthesized in the Magnetic Field Presence
}

\author{
L.E. Nita ${ }^{1}$, A.P. Chiriac ${ }^{*, 1}$, S. Cimmino ${ }^{2}$, C. Silvestre ${ }^{2}$, D. Duraccio $^{2}$ and C. Vasile ${ }^{1}$ \\ 1 "Petru Poni" Institute of Macromolecular Chemistry, 41 A Grigore Ghica Voda Alley, RO - 700487 Jassy, Romania; \\ ${ }^{2}$ Institute Of Chemistry and Technology Of Polymers, Via Campi Flegrei, 34, 80078 Pozzuoli, Italy
}

\begin{abstract}
The thermal behavior of polystyrene (PS) and of styrene copolymers with 2, 3 epoxypropyl methacrylate (GMA) synthesized in the presence of the magnetic field has been studied. The thermal behavior was investigated by thermogravimetry (TGA) and differential scanning calorimetry (DSC) techniques. The synthesized polymeric latexes were also characterized from the view point of the particle size distribution $(70-200 \mathrm{~nm})$ as well as of their stability by determining the zeta potential values. The decrease of zeta potential absolute value with the increase of GMA content or growth of the temperature it was observed. At the same time, the increase of zeta potential absolute value corresponds to latexes prepared in the MF presence. The presence of the magnetic field during syntheses increases the swelling capacities, glass transition temperature and thermal stability of both homopolymers as well as of the synthesized copolymers. The behavior was attributed to a potential ordered structure induced by the magnetic field during syntheses upon macromolecular chains.
\end{abstract}

\section{INTRODUCTION}

The emulsion polymerization of styrene photoinitiated by dibenzyl ketone or benzoin in the presence of a magnetic field (MF) evidenced the field effect upon the reaction kinetics [1-3]. The authors ascribed the increasing of the polymerization rate to the shortness of the polymer particle nucleation under the magnetic field influence. Also, the application of a moderate magnetic field (MF) of 50-1000 G significantly accelerated the polymerization process and resulted in an increase of the molecular weight of polystyrene formed in the emulsion polymerization [2-4]. These studies pointed out the importance of the radical pair mechanism as explanation for the magnetic field effects in reactions involving species having unpaired electrons [3-5]. Thus, the magnetic field influence becomes obvious when, in radical pairs from the system, the field will induce or prevent singlet - triplet transitions for example. The changes in the radical pairs' multiplicity are followed by modifications in the ratio of cage radicals to escape radicals. Consequently, the initiation and the kinetics of the reactions are affected. Micellar aggregates ideally fulfill the basic requirements for radical pair mechanism, namely easy separability of the geminate radical pairs followed by an extended period of diffusive reencounter. At the same time, the modification of the electronic spin alignment to the triplet state as a result of the magnetic field presence, determines the subsequent decrease of the radicals recombination process. This phenomenon of "micellar supercage effect" was evidenced and underlined by Turro [4].

In recent years, the copolymers based on 2, 3 - epoxypropyl methacrylate (GMA) received increased attention

*Address correspondence to this author at the "Petru Poni" Institute of Macromolecular Chemistry, 41 A Grigore Ghica Voda Alley, RO - 700487 Jassy, Romania; E-mail: achiriac1@yahoo.com owing to their versatile applications such as scaffolds for guided bone adhesives, for dentin bonding, application in immobilization and separation of biologically active substances, for obtaining powder coatings with better toughness, gloss, durability, chemical resistance, and flexibility [6-10]. The copolymerization kinetic of GMA with styrene in solution was studied in detail by Sorokin and Kochnov [11] and the reactivity ratio of the comonomer pair was reported. Zulfiqar and al. [9] investigated the thermal degradation behavior of GMA-styrene copolymer by employing various thermoanalytical techniques (thermal volatilization, thermogravimetry and subambient thermal volatilization analysis). They concluded that copolymers have intermediate thermal stability between polystyrene (PS) and poly(2, 3 - epoxypropyl methacrylate) (PGMA), a mechanism of thermal degradation being also suggested by the authors [9 - 14].

In our previous papers it was investigated the polymerization of styrene with 2, 3 - epoxypropyl methacrylate in a magnetic field of $0.25 \mathrm{~T}$, using different ratio between comonomers or concentrations of radical initiator, as well as various anionic surfactants in different reaction temperatures [5, 15-17]. The registered magnetokinetic effects were comparatively evaluated with the kinetic parameters achieved during classic polymerization. It was established that magnetic field affects both kinetic parameters of the reactions as well as some characteristics of the synthesized compounds [17]. It was evidenced the increase of the process conversion and of the polymerization rate as a result of the magnetic field presence during syntheses. The present study is focused on the effect of the MF upon some properties of the synthesized polymers based on styrene and 2, 3- epoxypropyl methacrylate, especially on their thermal behavior. 
Table 1. Recipe for Latex Preparation

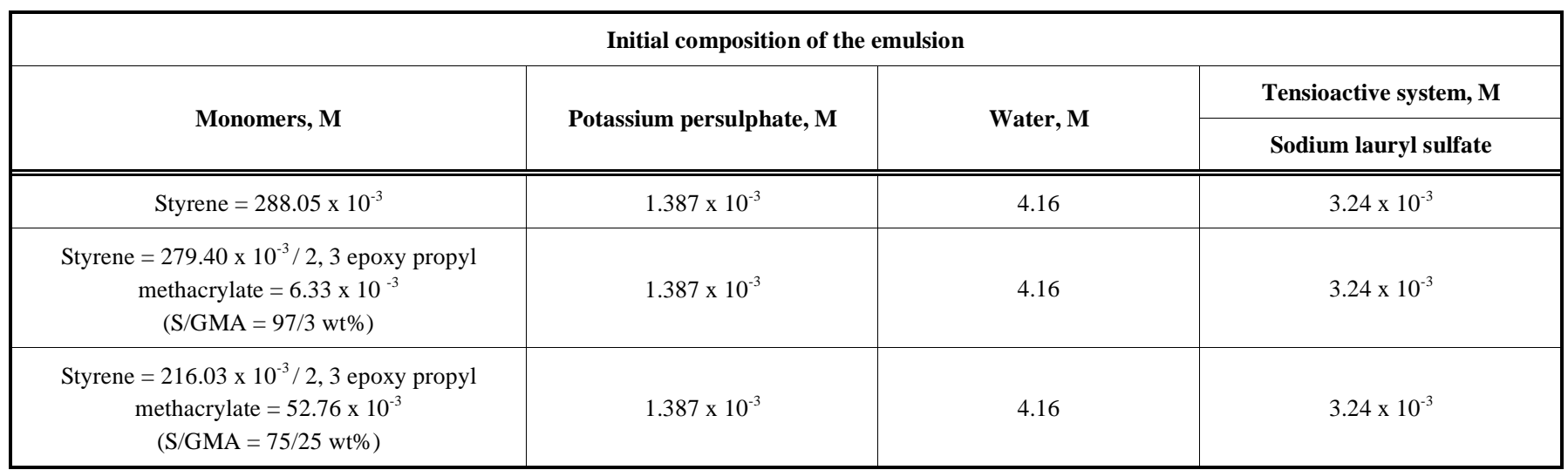

Reaction conditions: - temperature: $70^{\circ} \mathrm{C}$; - time: 7 hours.

The initiator represents $0.8 \mathrm{wt} \%$ with respect to monomer amount.

The tensioactive substance represents 3 wt \% with respect to monomer amount.

\section{EXPERIMENTAL PART}

\section{Materials}

The monomers - styrene and 2, 3 - epoxypropyl methacrylate both from Fluka - were freshly distilled before use.

The tensioactive agent - sodium lauryl sulfate $\left(\mathrm{C}_{12} \mathrm{H}_{25} \mathrm{O}_{4} \mathrm{SNa}\right)$-(SLS) from Sigma (c > $\left.95 \mathrm{wt} \%\right)$ - was used without further purification.

The initiator potassium persulphate $\left(\mathrm{K}_{2} \mathrm{~S}_{2} \mathrm{O}_{8}\right)-(\mathrm{KPS})$ was twice recrystallized from twice distilled water.
In all experiments it was used twice distilled water which contained no foreign ions.

\section{Polymerization Process}

The emulsion polymerization technique performed classically $(\mathrm{CW})$ and in the magnetic field presence (MF) was described in detail in previous papers [15-17].

Polymerization process of $\mathrm{S}$ and respectively between $\mathrm{S}$ and GMA, for both variants of synthesis with the MF presence or without the field presence $(\mathrm{CW})$, took place accordingly to the reaction conditions mentioned in Table $\mathbf{1}$.

Table 2. Spectral Data of the PS and S-GMA Copolymers Synthesized by CW and in MF Presence

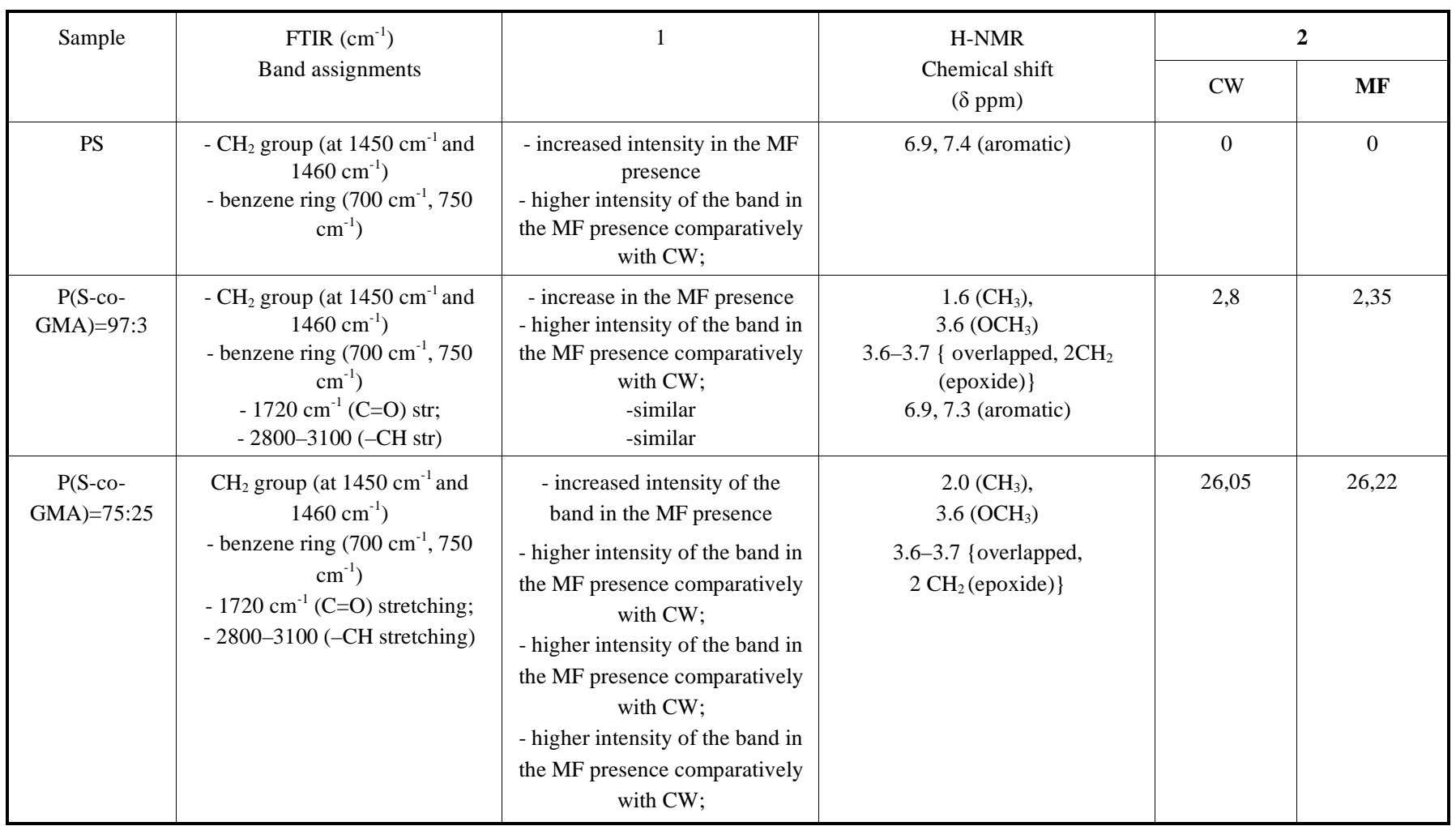

1 - Differences observed in spectra of compounds obtained in MF presence.

2 - GMA in copolymer \% determined from NMR spectra. 
The polymerization in MF was performed in a field of $1500 \mathrm{G}$ intensity and in the same conditions with classic variant: similar vessel shape and geometry, the same reaction parameters and type of stirring.

The polymers were precipitated in methanol, dried under vacuum at room temperature for 48 hours and stored in the desiccator.

The molecular structures via the bands' identification from the FTIR spectra (recorded on a DIGILAB, Scimitar Series, USA, spectrophotometer, the resolution was $4 \mathrm{~cm}^{-1}$ ) have been used (concentration $3 \mathrm{mg}$ sample in $500 \mathrm{mg} \mathrm{KCl}$ tablet). The composition of each copolymer was determined from $1 \mathrm{H}$ - NMR data.

Table 2 presents the characteristic bands in FT-IR and composition for the copolymers synthesized by classic way $(\mathrm{CW})$ and in magnetic field (MF) way.

Spectroscopic characterization (Table 2) confirms the presence of both monomers in copolymers structure in amounts close to those employed in the reaction feed. As it is expected, the bands corresponding to GMA comonomer (1720 $\mathrm{cm}^{-1}$ and $2800-3100 \mathrm{~cm}^{-1}$ ) increase with its content. Some indications about structural differences in the copolymers synthesized in MF presence in respect with those prepared by $\mathrm{CW}$ are also evidently. Thus, several bands show higher intensities $\left(700 \mathrm{~cm}^{-1}, 750 \mathrm{~cm}^{-1}, 1720 \mathrm{~cm}^{-1}\right.$, and $2800-$
$3100 \mathrm{~cm}^{-1}$ ) probably because of much ordered structure. In the case of the copolymers with low percent of GMA the influence of the MF on the spectral band intensity is not so evidently. With the increase of GMA percent the intensity of the adsorption characteristic bands $\left(1720 \mathrm{~cm}^{-1}\right.$, and $2800-$ $3100 \mathrm{~cm}^{-1}$ ) became higher.

The higher intensities of the vibration oscillations absorption are attributed to the modification of the strength constant introduced by the inductive and electromeric effects rising supplementary in the polymeric structure achieved in the conditions of the magnetic field. Thus, the modifications occurring in rotational spectra respectively the increase of the intensity of the vibration oscillations absorption, as well as shifting of peaks, are explained by the orientation of the nuclear spins, molecular structure and interactions between them (these aspects being depicted by IR spectra also by other authors [18]).

Swelling behavior determination: The swelling of dried polymer particles was performed in chloroform vapors at $20^{\circ} \mathrm{C}$ and 2 torr. The organic solvent absorbed was determined by weighing the samples, at various intervals of time, with a precision electronic balance (A\&D Co. Ltd. HR 200).

DSC curves were recorded with a heat flow Mettler Toledo DSC-822 under inert atmosphere of nitrogen. The following procedure of heating/cooling was used:


Scheme 1. 
$-1^{\text {st }}$ cooling: the samples were cooled from 25 to $-70^{\circ} \mathrm{C}$ at $20^{\circ} \mathrm{C} / \mathrm{min}$; kept at $-70^{\circ} \mathrm{C}$ for $1 \mathrm{~min}$.

$-1^{\text {st }}$ heating run: one sample was heated from -70 to $150^{\circ} \mathrm{C}$ with a heating rate of $20^{\circ} \mathrm{C} / \mathrm{min}$; kept at $150^{\circ} \mathrm{C}$ for $1 \mathrm{~min}$; this sample is labeled as sample (150/1'); the second sample was heated up to $180^{\circ} \mathrm{C}$ and kept for $1 \mathrm{~min}$, labeled as sample (180/1'); the third sample was kept at $180^{\circ} \mathrm{C}$ for 5 ' and labeled as sample (180/5').

$-2^{\text {nd }}$ heating run: after the I Run, the samples, were cooled at a cooling rate of $50^{\circ} \mathrm{C} / \mathrm{min}$ to $-70^{\circ} \mathrm{C}$ and kept for $1 \mathrm{~min}$.

-II RUN: the samples were finally heated to $180^{\circ} \mathrm{C}$ at $20^{\circ} \mathrm{C} / \mathrm{min}$.

$\mathrm{Tg}$ values are read at the inflection point on the thermoanalytical curves.

Thermo-gravimetric analysis was performed in nitrogen atmosphere in the temperature range from $30^{\circ} \mathrm{C}$ to $700^{\circ} \mathrm{C}$ by means of TGA 851 Mettler. Two heating rates were used: 5 and $20^{\circ} \mathrm{C} / \mathrm{min}$. Two recordings were performed for each experiment.

The $\zeta$ potential was determined on a Malvern Zetasizer Nano ZS instrument. The $\zeta$ potential was appreciated from the electrophoretic mobility $(\mu)$ using the Smoluchowski relationship,

$\xi=\eta \mu / \varepsilon$, where $k \alpha>>1$

where $\eta$ - viscosity, $\varepsilon$ - dielectric constant of the medium, $\mathrm{k}$ and $\alpha$ are Debye-Hückel parameter and the particle radius, respectively. Each analysis was made for three times and the average value it is obtained.

The particles size distribution analysis was made by laser diffraction measurement on the Mastersizer Hydro 2000S (Malvern Instrument UK) particles analyzer. The laser obscuration was kept constantly in the range of $8-12 \%$. Each analysis was made for five times and the average value it is presented.

\section{RESULTS AND DISCUSSION}

In our previous papers [15-17] it was presented a comparative study regarding the magnetic field influence upon the copolymerization reaction of styrene with 2,3 - epoxypropyl methacrylate using radical emulsion polymerization procedure. It was established that magnetic field affects both kinetic parameters of synthesis as well as some characteristics of the synthesized compounds [17]. Thus it was evidenced the increase of the conversion and of the polymerization rate as a result of the magnetic field presence during polymers' synthesis. This study is focused on the effect of the MF upon the properties of the synthesized polymers, especially on their thermal behavior.

\section{The Swelling Study}

A fundamental relationship exists between the swelling of a polymer in a solvent and the nature of polymer and solvent. The percentage swelling ratio $(\% \mathrm{~S})$ was calculated from the following equation:

$\% S=\frac{M_{t}-M_{o}}{M_{o}} \times 100$ where $M_{t}$ is the weight of the swollen polymer at time t and $M_{o}$ being the weight of the dried polymer at time 0 . The solvent uptake by the initially dried polymers was pursued approximately for 30 hours, until equilibrium. The swelling curves are plotted in Figs. (1a, b).
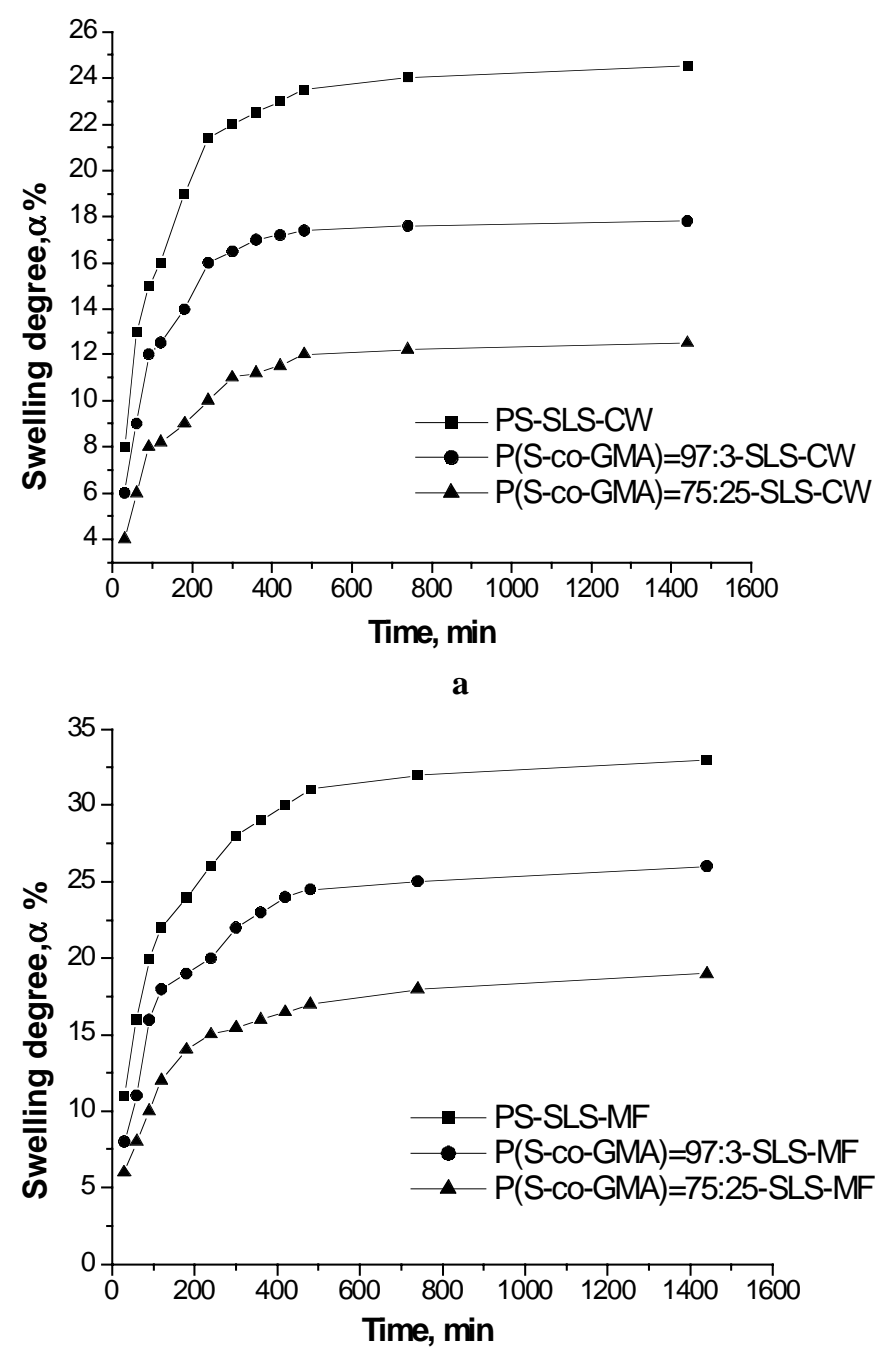

b

Fig. (1). Swelling degree of the samples obtained by $\mathrm{CW}$ (a) and in MF presence (b) polymerization.

It is evidently an increase in the swelling degree until 500-600 min; relatively constant values were obtained after this time, when the swelling equilibrium was reached.

Although chloroform is a solvent for PS, the polymeric matrices obtained in the mentioned reaction conditions are not soluble in it. This fact was attributed to the crosslinking reactions performed between the macromolecular chains owing to the synthesis procedure (Scheme 1): five hours reaction time at $75^{\circ} \mathrm{C}(90 \%$ conversion has been obtained just after two hours of reaction) and one hour heating treatment at $85^{\circ} \mathrm{C}$. The explanation is also supported by the fact that polymeric samples after 2 hours of reaction time are still soluble in chloroform but after 7 hours they became insoluble. The intention of the study was to obtain polymeric networks designed to special applications: as matrices to entrap different active substances. 
Table 3. The Swelling Rate of the Copolymers (Swelling Rate $\mathbf{x 1 0}^{-3} \% \mathrm{~min}^{-1}$ )



The obtained profiles illustrate the diverse swelling capacities of the synthesized polymers in the solvent. The data allow the establishment of the optimum interval of time in order to achieve a polymeric network with maximum relaxed structure. By comparing the swelling curves in Fig. (1a and 1b) it is evidently the polymeric matrices synthesized by $\mathrm{CW}$ present a reduced relaxation capacity with respect to the samples synthesized in MF. The polymeric matrices synthesized in MF have the same shape of the swelling curves, but the swelling degree is higher than the corresponding one obtained by $\mathrm{CW}$. Particularly, the swelling degree in MF increases with $\sim 8.5 \%$ for $\mathrm{PS}, \sim 8 \%$ for the $\mathrm{P}(\mathrm{S}-\mathrm{co}-\mathrm{GMA})=$ $97: 3$ copolymer and $\sim 6.5 \%$ for the $\mathrm{P}(\mathrm{S}-\mathrm{co}-\mathrm{GMA})=75: 25$ copolymer comparatively with the swelling degree of the same samples obtained by $\mathrm{CW}$. The changes are attributed to a lower cross-linking degree of the samples synthesized in MF presence, which is evidenced by the higher swelling degree of the samples polymerized in MF presence with respect to those obtained by CW. Also, it is well known that the magnetic field influence can be conceived like a catalytic effect, producing the molecules' distortions, the growth of distance interactions and the modifications of the angles between the bonds as well as inducing the modification of the strength constant introduced by the inductive and electromeric effects appearing supplementary in the polymeric structures obtained in the conditions of the magnetic field.

The comparison was made between the samples taken after 1 hour of the polymerization time.

From Table 3 it can be observed for MF samples, the swelling rate and $\alpha_{\max }$ (the maximum degree of swelling) are higher than those of CW samples.

\section{The Thermal Behavior}

DSC curves of the samples prepared by classical way (CW) and in the magnetic field (MF), are given in Fig. (2).

Fig. (2a) reports the second run curves after annealing the samples at $180^{\circ} \mathrm{C}$ for $5 \mathrm{~min}$. The curves obtained with the other two annealing processes (not shown) are qualitatively similar to those exposed in Fig. (2), the differences appearing in the value of the glass transition temperature, $\mathrm{Tg}$. In fact, Tg's found in $2^{\text {nd }}$ run curves depends on the performed annealing history, as it is reported in Table 4.

For the $\mathrm{CW}$ samples an increase of $\mathrm{Tg}$ when temperature raises from 150 to $180^{\circ} \mathrm{C}$, it is detected. For PS - CW sample it is observed an increase of $\mathrm{Tg}$ value from 86 to $91-92^{\circ} \mathrm{C}$, as the temperature is raised from 150 to $180^{\circ} \mathrm{C}$. The two treatment times at $180^{\circ} \mathrm{C}$ do not have any influence on $\mathrm{Tg}$ value. The annealing at $150^{\circ} \mathrm{C}$ for 1 min does not induce a change in $\mathrm{Tg}$ values of the copolymers synthesized by $\mathrm{CW}$ in respect to $\mathrm{PS}-\mathrm{CW}$. For $\mathrm{P}(\mathrm{S}-\mathrm{co}-\mathrm{GMA})=97: 3 \mathrm{CW}$ copolymer, after the treatment at $180^{\circ} \mathrm{C}$ for $1 \mathrm{~min}, \mathrm{Tg}$ value is $90^{\circ} \mathrm{C}$ and became $\mathrm{Tg}=93^{\circ} \mathrm{C}$ by heating for $5 \mathrm{~min}$. The heating of the copolymers with $25 \%$ of GMA at $180^{\circ} \mathrm{C}$ for 1 min induces an increase of $\mathrm{Tg}$ at $96^{\circ} \mathrm{C}$ and $98^{\circ} \mathrm{C}$ for heating for $5 \mathrm{~min}$. By



$\mathbf{a}$

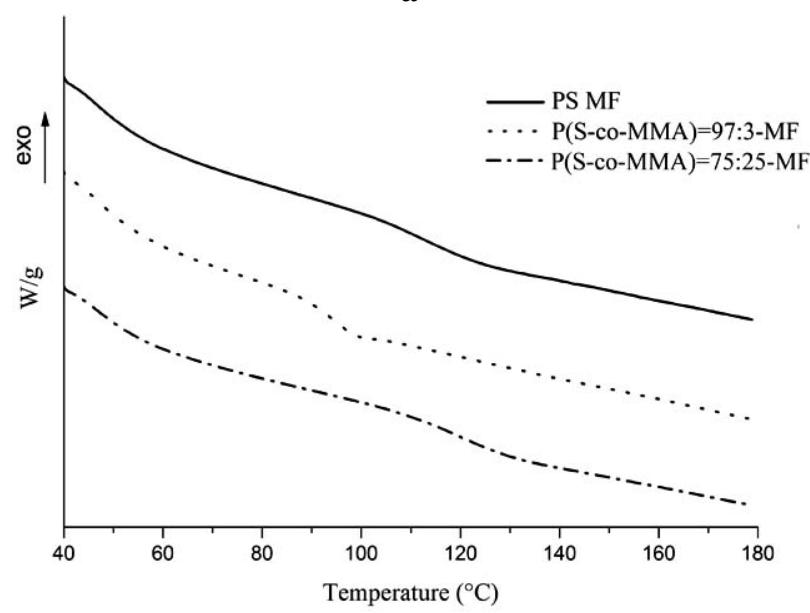

b

Fig. (2). DSC curves for PS and PS - co - GMA samples after the treatment at $180^{\circ} \mathrm{C}$ for $5 \mathrm{~min}$ : a) Samples synthesized in $\mathrm{CW}-2^{\text {nd }}$ run; b) Samples synthesized in MF - $2^{\text {nd }}$ run. 
Table 4. Tg Detected in $2^{\text {nd }}$ Run DSC Curves $\left( \pm 1^{\circ} \mathrm{C}\right)$

\begin{tabular}{|c|c|c|c|}
\hline Sample & After $150^{\circ} \mathrm{C}$ for 1 , & After $180^{\circ} \mathrm{C}$ for 1 , & After $180^{\circ} \mathrm{C}$ for $5^{\prime}$ \\
\hline PS- MF & 100 & 112 & 124 \\
\hline $\mathrm{P}(\mathrm{S}-\mathrm{co}-\mathrm{GMA})=97: 3-\mathrm{CW}$ & 87 & 90 & 93 \\
\hline $\mathrm{P}(\mathrm{S}-\mathrm{co}-\mathrm{GMA})=97: 3-\mathrm{MF}$ & 91 & 94 & 94 \\
\hline
\end{tabular}

looking along the path from the left to the right $\left(150^{\circ} \mathrm{C} / 1^{\prime}\right.$, $180^{\circ} \mathrm{C} / 1^{\prime}$ and $\left.180^{\circ} \mathrm{C} / 5^{\prime}\right), \mathrm{Tg}$ values increase with rising temperature and time of annealing. Moreover, it is possible to conclude that $\mathrm{Tg}$ obtained on the II Run curves, for a fixed composition, depends on the thermal history: $\mathrm{Tg}$ increases with the temperature and the time of heating.

At the same time, $\mathrm{Tg}$ values of $\mathrm{CW}$ samples, at any fixed thermal history, increase with GMA content of the copolymer. The only value - out of this trend - is for the copolymer with 3 wt $\%$ GMA $-180^{\circ} \mathrm{C} / 1^{\prime}$ that shows $\mathrm{Tg}$ of $90^{\circ} \mathrm{C}$, whereas the PS $\left(180^{\circ} \mathrm{C} / 1^{\prime}\right)$ presents $\mathrm{Tg}$ at $92^{\circ} \mathrm{C}$.

From Table 4, for the samples synthesized in MF it can be observed that Tg for PS significantly increases with tem-

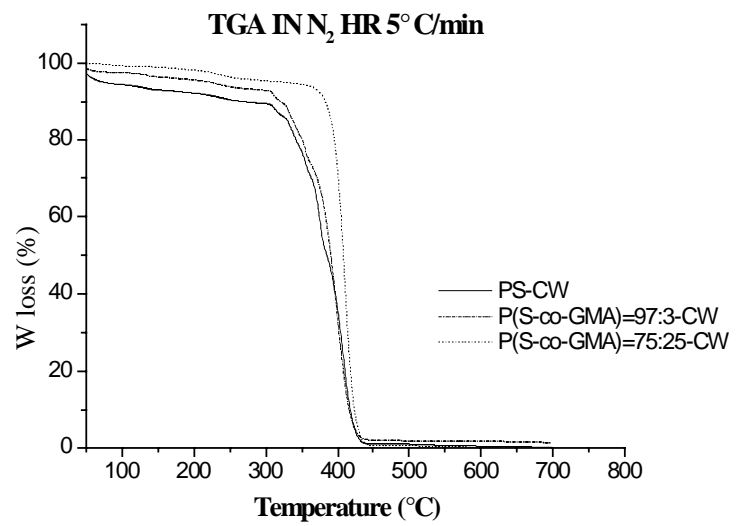

a perature and time, from $100^{\circ} \mathrm{C}$ (when the heating is performed at $150^{\circ} \mathrm{C}$ for $1^{\prime}$ ), to $112^{\circ} \mathrm{C}$ (when the heating is done at $180^{\circ} \mathrm{C}$ for $1^{\prime}$ ) and to $124^{\circ} \mathrm{C}$ (when the heating is done at $180^{\circ} \mathrm{C}$ for $\left.5^{\prime}\right)$.

The same trend is found for $\mathrm{P}(\mathrm{S}-\mathrm{co}-\mathrm{GMA})=75: 25-\mathrm{MF}$ variant, where the sample treated already at $180^{\circ} \mathrm{C}$ for 1 ' presents $\mathrm{Tg}$ at $121^{\circ} \mathrm{C}$. A greater time of heating (5') does not induce any further significant change in $\mathrm{Tg}$, its value being kept at $122^{\circ} \mathrm{C}$.

The trend for $\mathrm{P}(\mathrm{S}-\mathrm{co}-\mathrm{GMA})=97: 3-\mathrm{MF}$ sample is different. The increase is small, from $91{ }^{\circ} \mathrm{C}$ (when the heating is performed at $150^{\circ} \mathrm{C}$ for $1^{\prime}$ ) to $94^{\circ} \mathrm{C}$ (when the heating is done at $180^{\circ} \mathrm{C}$ for $\left.5^{\prime}\right)$. It can also be observed when the sam-

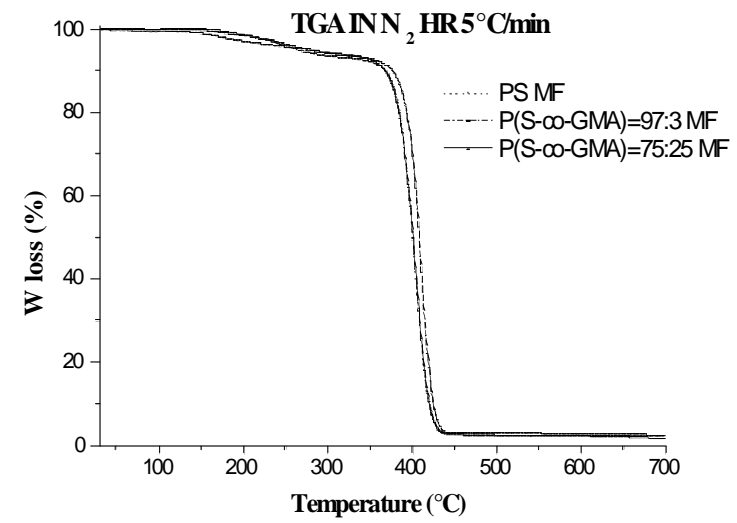

b

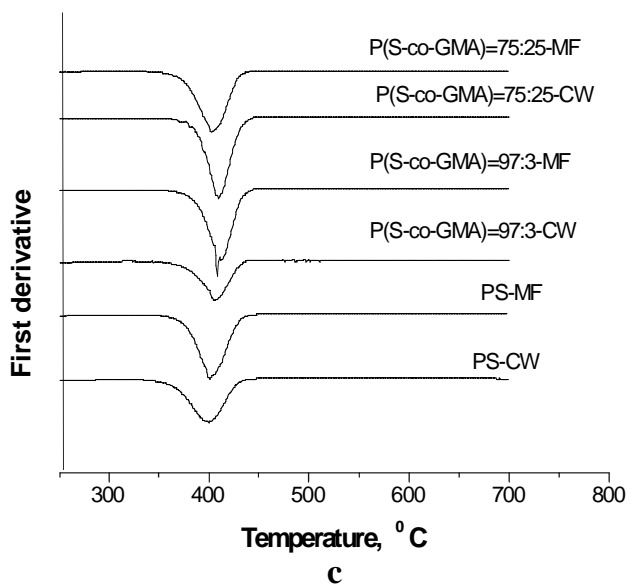

Fig. (3). TGA curves for PS and copolymers of styrene with GMA polymerized by CW (a), in MF presence (b) and DTG curves of all the studied samples (dynamic atmosphere of nitrogen $\mathrm{mL} / \mathrm{min}$ at a heating rate of $5^{\circ} \mathrm{C} / \mathrm{min}$ ). 
ples are synthesized in MF, a lower amount of GMA in the copolymer determines a decrease of $\mathrm{Tg}$ value in respect to that of neat PS at every annealing. With the increase of GMA content, Tg value becomes higher. The observed increase of Tg with temperature and time of annealing is usually attributed to an increase of the molecular weight, as a consequence of polymerization not completely occurred or to the appearance of new crosslinks. The measurements of the conversion reported in another paper [15] indicated a higher conversion (up to 90\%), especially for the samples synthesized in MF presence. So, it can be concluded for the samples with higher content of GMA, the increasing of temperature is due to the appearance of supplementary transversal bridges. At the same time, the increase of Tg temperature for the homopolymers could be explained by the ordering MF induces in the structure. The exception remains the sample with lower GMA content.

If the samples synthesized in CW are compared with the samples synthesized in MF, it can be resumed for all the annealing pathways, MF samples have higher Tg values regardless of the used annealing procedure. The highest increase of Tg with 33 degrees is observed for PS samples.

In Figs. (3 and 4) the thermogravimetric curves recorded at $5^{\circ} \mathrm{C} / \mathrm{min}$ and $20^{\circ} \mathrm{C} / \mathrm{min}$ for the samples obtainment both in

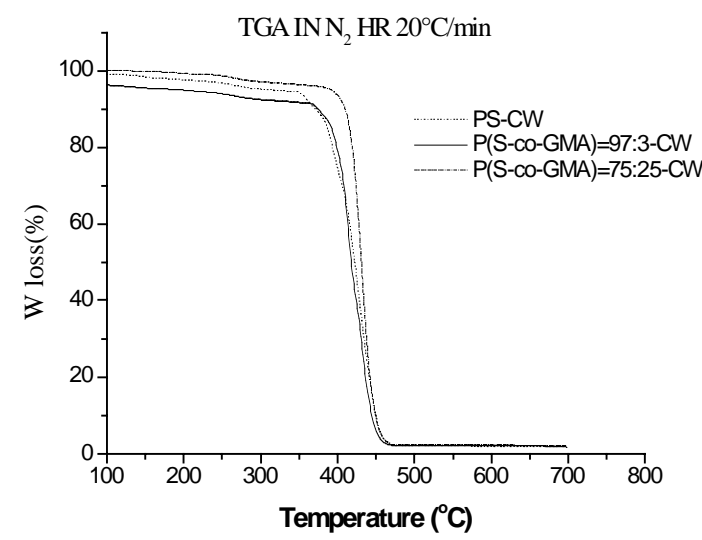

a
$\mathrm{CW}$ and $\mathrm{MF}$, are reported. The main step of degradation is identical for all the polymers.

It can be observed the degradation of $\mathrm{CW}$ synthesized samples starts at lower temperatures in respect to that of samples synthesized in MF. The difference is more pronounced for the curves obtained at the heating rate of $5^{\circ} \mathrm{C} / \mathrm{min}$.

To underline the higher thermal stability of MF samples comparatively with $\mathrm{CW}$ samples, there were reported in Table 5 the onset temperature $\left(\mathrm{T}_{\mathrm{i}}\right)$, the temperature corresponding to the maximum rate of the mass loss ( $\left.\mathrm{T}_{\mathrm{MAX}}\right)$, and the weight loss $(\Delta \mathrm{w})$.

$\mathrm{T}_{\max }$ and $\mathrm{T}_{\mathrm{i}}$ temperatures for the samples obtained in $\mathrm{MF}$ are higher than those of the samples obtained by $\mathrm{CW}$, while the mass losses are lower.

An increase of the overall activation energy (Coats Redfern [19]) of PS decomposition for the samples obtained by $\mathrm{CW}$ and in MF presence respectively, was found of about $10-15 \mathrm{KJ} / \mathrm{mol}$ (from $80 \mathrm{KJ} / \mathrm{mol}$ to $95 \mathrm{KJ} / \mathrm{mol}$ ) for sample obtained in MF presence, while for copolymers the increase is smaller of $5-7 \mathrm{KJ} / \mathrm{mol}$ for samples obtained by $\mathrm{CW}$ and in $\mathrm{MF}$ presence respectively (from $45 \mathrm{KJ} / \mathrm{mol}$ to $50 \mathrm{KJ} / \mathrm{mol}$ ).



b

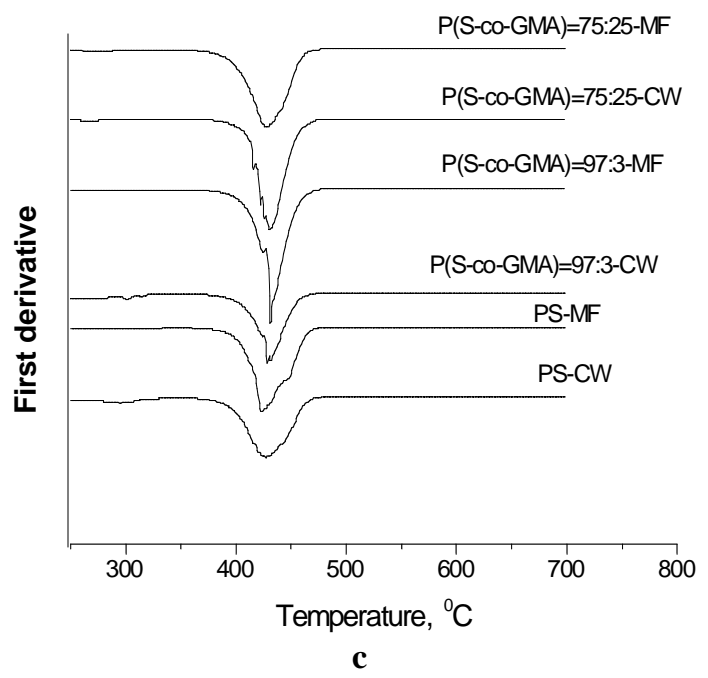

Fig. (4). TGA curves for PS and styrene with GMA copolymers polymerized by CW (a), in MF presence (b) and DTG curves of all studied samples (dynamic atmosphere of nitrogen $\mathrm{mL} / \mathrm{min}$ at a heating rate of $20^{\circ} \mathrm{C} / \mathrm{min}$ ). 
Table 5. Characteristic Temperature of Decomposition and Mass Losses of the Samples Synthesized in CW and in MF Presence

\begin{tabular}{|c|c|c|c|c|c|c|c|c|c|c|}
\hline \multirow[t]{3}{*}{ Sample } & \multicolumn{4}{|c|}{ HR $5^{\circ} \mathrm{C} / \min \left({ }^{\circ} \mathrm{C}\right)$} & \multicolumn{4}{|c|}{ HR $20^{\circ} \mathrm{C} / \mathrm{min}\left({ }^{\circ} \mathrm{C}\right)$} & \multirow{2}{*}{\multicolumn{2}{|c|}{$\Delta \mathrm{W} \%$}} \\
\hline & \multicolumn{2}{|c|}{$\mathbf{T i}^{\circ} \mathrm{C}$} & \multicolumn{2}{|c|}{$\operatorname{Tmax}^{\circ} \mathbf{C}$} & \multicolumn{2}{|c|}{$\mathrm{Ti}^{\circ} \mathrm{C}$} & \multicolumn{2}{|c|}{$\operatorname{Tmax}^{\circ} \mathbf{C}$} & & \\
\hline & CW & MF & CW & MF & CW & MF & $\mathbf{C W}$ & MF & $\mathrm{C}$ & $\mathbf{C M}$ \\
\hline PS & 352 & 368 & 399 & 400 & 370 & 380 & 427 & 420 & 83 & 81 \\
\hline $\begin{array}{c}\text { P(S-co-GMA }) \\
97: 3\end{array}$ & 370 & 375 & 402 & 404 & 390 & 392 & 430 & 435 & 89.5 & 86.7 \\
\hline $\begin{array}{c}\text { P(S-co-GMA) } \\
75: 25\end{array}$ & 375 & 375 & 408 & 402 & 396 & 394 & 430 & 430 & 84 & 70 \\
\hline
\end{tabular}

The influence of MF on the thermal behavior could be explained by the pre-ordered - structure of the copolymers as a result of the magnetic field presence during the synthesis $[18,20]$.

Structural and morphological studies are in progress to confirm this hypothesis.

\section{The Particles Size Distribution}

An analysis of the polymeric latex is given in Fig. (5):

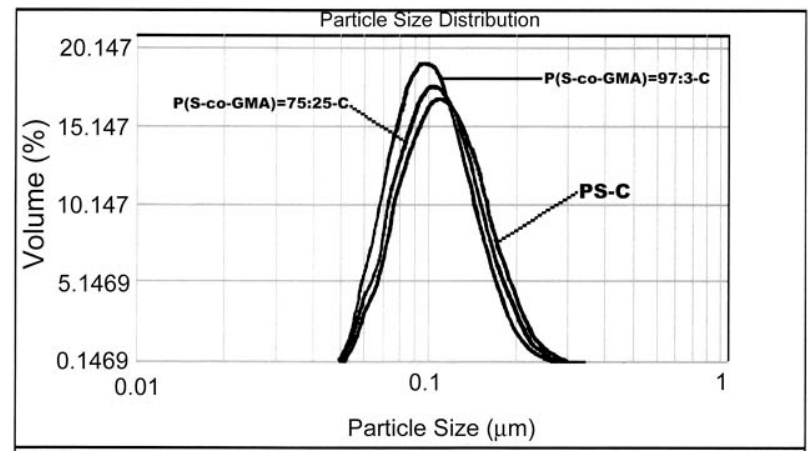

$\mathbf{a}$

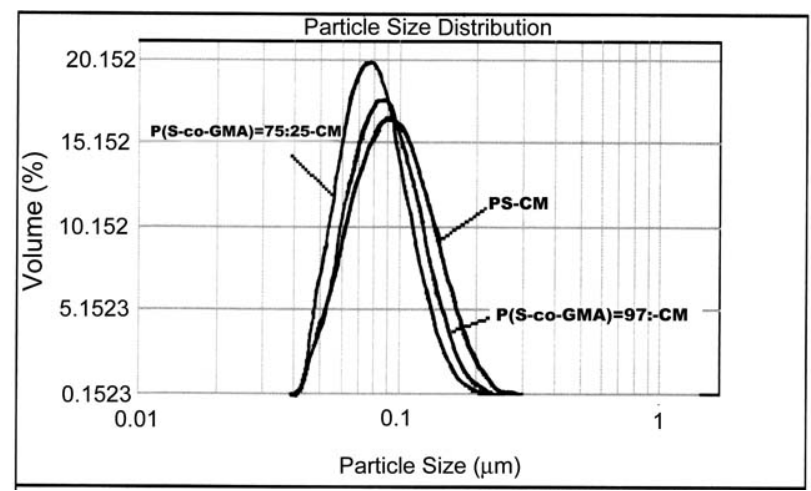

b

Fig. (5). The particle size distribution of the samples synthesized by classical way (a) and in MF presence (b).

The particle size distribution analyses indicated a relatively narrow distribution between 70nm-200nm (Fig. 5). The median diameter value - MMD (which indicated the point at which $50 \%$ of distribution is both above and below) is given in Table $\mathbf{6}$.

\section{The Zeta Potential Measurement}

The stability of particle dispersion depends on the balance of the repulsive and attractive forces that exists between the particles, as they approach one another. If the particles have a mutual repulsion then the particles will remain dispersed. However, if the particles have little or no repulsive force, they flocculate, aggregate or coalescence. The magnitude of the zeta potential of the particles is a measure of this interaction. When the zeta potential is greater than $30 \mathrm{mV}$ there is sufficient charge presented to keep away the particles from interaction and the dispersion, and therefore the size of the sample, remains stable. This is the case of our synthesized latex. The potential value range between $-30 \mathrm{mV}$ and $51.9 \mathrm{mV}$ (see Table 6), emphasizing the obtainment of the stable latex.

Nanoparticles with higher negative value of potential would be advantageous, especially in drug delivery to the lymphatic system, since the negatively charged hydrophobic particles undergo increased uptake by the lymphatic capillaries [21]. Owing to their hydrophobicity, these particles undergo opsonization and uptake by macrophages after intravenous administration, and may further result in increased lymphatic concentration [22].

The higher negative value of potential is attributed to the potassium persuphate presence [23] and to the anionic surfactant used, too.

The data presented in Table $\mathbf{6}$ show a decrease of zeta potential absolute value with the increase of GMA percent and of the temperature. At the same time an increase of the potential absolute value in MF presence is appeared. This behavior is attributed to the negative charge at the particles surface which is more ordered in the MF presence.

The fact the absolute potential value doesn't decrease below to $30 \mathrm{mV}$ demonstrates the good stability of the synthesized latex, even at the increased temperature of $37 \mathrm{oC}$ and higher GMA content (25\%).

The latex conductivity (see Table 6) illustrates a higher value with temperature and with GMA content. At the same time MF presence determined a lower conductivity. These changes in the properties of the polymers synthesized in the magnetic field are attributed to the catalytic effect of the field on the molecules that can be re-shaped through growing 
Table 6. The Median Diameter, Zeta Potential and Conductivity of the Latex Synthesized by CW and in MF Presence

\begin{tabular}{|c|c|c|c|c|c|c|c|c|c|c|}
\hline \multirow[t]{3}{*}{ Sample } & \multicolumn{2}{|c|}{ MMD (nm) } & \multicolumn{4}{|c|}{ Zeta potential, $\zeta(\mathrm{mV})$} & \multicolumn{4}{|c|}{ Conductivity mS/cm } \\
\hline & \multirow[t]{2}{*}{ CW } & \multirow[t]{2}{*}{ MF } & \multicolumn{2}{|c|}{ CW } & \multicolumn{2}{|c|}{ MF } & \multicolumn{2}{|c|}{ CW } & \multicolumn{2}{|c|}{ MF } \\
\hline & & & $22^{\circ} \mathrm{C}$ & $37^{\circ} \mathrm{C}$ & $22^{\circ} \mathrm{C}$ & $37^{\circ} \mathrm{C}$ & $22^{\circ} \mathrm{C}$ & $37^{\circ} \mathrm{C}$ & $22^{\circ} \mathrm{C}$ & $37^{\circ} \mathrm{C}$ \\
\hline PS & 98 & 100 & -45.2 & -40.1 & -51.9 & -42 & 0.087 & 0.094 & 0.068 & 0.070 \\
\hline $\begin{array}{c}\text { P(S-co GMA }) \\
=97: 3\end{array}$ & 98 & 110 & -37.9 & -35.2 & -50.6 & -40 & 0.1 & 0.105 & 0.07 & 0.072 \\
\hline $\begin{array}{l}\mathrm{P}(\mathrm{S} \text {-co GMA }) \\
\quad=85: 15\end{array}$ & 115 & 116 & -43 & -36 & -45.2 & -32.5 & 0.106 & 0.116 & 0.07 & 0.074 \\
\hline $\begin{array}{c}\mathrm{P}(\mathrm{S}-\text {-co-GMA }) \\
=75: 25\end{array}$ & 96 & 97 & -32 & -30 & -43 & -36.8 & 0.110 & 0.119 & 0.089 & 0.098 \\
\hline
\end{tabular}

of distance interactions and reducing thus the mobility and also the modification of angles between bonds as well as inducing a preordered structure [24].

\section{CONCLUSIONS}

PS as well as styrene copolymers with a monomer bearing functional groups - GMA, have been obtained by classical way and in MF presence emulsion polymerization. The polymeric latex is obtained with narrow distribution (70-200 $\mathrm{nm}$ ) as characterized from potential zeta point of view. A decrease of zeta potential absolute value with the increase of GMA percent and of the temperature it was observed. At the same time, an increase of the potential absolute value in MF presence is appeared.

It has been established that the presence of the magnetic field during emulsion polymerization of styrene and of styrene copolymerization with GMA allows obtaining polymers with higher swelling capacities, glass transition temperatures and thermal stabilities. The influence of MF on thermal behavior was attributed to the pre-ordering-structure of the macromolecular chains as a result of the magnetic field presence during the synthesis.

The study was supported by the Project ID_995 entitled "Researches in the field of polymeric matrices design for sensitive structures" through IDEI PROGRAM

\section{REFERENCES}

[1] Salikhov, K.M.; Molin, Yu. N.; Sagdeev, R.Z.; Buchachenko, A.L. Spin Polarization and Magnetic Effects in Radical Reactions, Elsevier Press, Amsterdam,1984.

[2] Steiner, U.E.; Ulrich, T. Magnetic field effects in chemical kinetics and related phenomena. Chem. Rev., 1989, 89, 51-147.

[3] Steiner, U.E.; Wolff, H.J. Photochemistry and Photophysics, CRCPress, Boca Raton, Boston, 1991, vol. IV, 1-126.

[4] Turro, N. J.; Chow, M.-F.; Chung, C.-J.; Tung, C.-H. An efficient, high conversion photoinduced emulsion polymerization. Magnetic field effects on polymerization efficiency and polymer molecular weight. J. Am. Chem. Soc., 1980, 102, 7391-7395.

[5] Chiriac, A. P.; Simionescu, C.I. Magnetic field polymerisation. Prog. Polym. Sci., 2000, 25(2), 219-258.

[6] Nishikubo, T.; Saita, S.; Fujii, T. New thermo-crosslinking reactions of polymers containing pendant epoxide groups with variouspolyfunctional active esters. J. Polym. Sci. Part A, 1987, 25(5), $1339-1351$.
[7] Dhal, P.K.; Babu, G.N. Epoxy functional copolymers as biospecific adsorbents for purification of enzymes, J. Polym. Sci. Polym. Chem. Ed., 1985, 23, 319-325.

[8] Zulfiqar, S.; Zulfiqar, M.; Nawaz, M. Thermal-degradation of poly(glycidyl methacrylate). Polym. Degrad. Stab., 1990, 30(2), 195-203.

[9] Zulfiqar, M.; Paracha, A.; Zulfiqar, S. Thermal degradation of glycidyl methacrylate-styrene copolymers. Polym. Degrad. Stab., 1994, 43, 403-408.

[10] Pokorska-Młodzińska, O.; Pokorska, Z.; Spadło, M. Thermal and dielectric properties of some epoxy compositions. Polimery, 2007, 2, 127-130.

[11] Shyichuk, A.; Piszczek, K.; Rokitnicka, J. Rapid communication, recovery of mechanical properties of aged polystyrene after reprocessing. Polimery, 2006, 5, 156-158.

[12] Górczyk, J.; Bogdał, D.; Pielichowski, J.; Penczek, P. Increased molecular weight epoxy resins - syntheses and thermal haracteristics. Polimery, 2006, 11/12.

[13] Ahmad, S.; Zulfiqar, S. Synthesis, characterization and thermal degradation of glycidyl methacrylate- $\alpha$-methyl styrene copolymers. Polym. Degrad. Stab., 2002, 76, 173-177.

[14] McNeill, I.C. Developments in Polymer Degradation. Eur. Polym. J., 1970, 6, 373-395.

[15] Nita, L.E.; Chiriac, A.P. Possibilité d'obtention des copolymères à base de styrène et 2,3-epoxy-propyl-methacrylate dans le champmagnétique. Proceedings at COFrRoCA, Slanic Moldova, Romania, 2004, pp. 574-578.

[16] Nita, L.E.; Chiriac, A.P. A comparative study regarding the magnetic fields effect in the copolymer poly(styrene - co - 2,3epoxypropyl methacrylate). West Univ. Ann., 2003, 42(22), 19-23.

[17] Nita, L.E.; Chiriac, A.P. Polymerization in a magnetic field. 17. $J$. Appl. Polym. Sci, 2007, 104, 3029-3035.

[18] Chiriac, A.P. Polymerization in a magnetic field. 14. Possibilities to improve field effect during methyl acrylate polymerization. J. Appl. Polym. Sci., 2004, 92(2), 1031-1036.

[19] Coats, A.W.; Redfern, J.P. Kinetic parameters from thermogravimetric data. Nature, 1964, 201, 68-69.

[20] Chiriac, A.P. Polymerization in magnetic field. XVI. Kinetic aspects regarding methyl methacrylate polymerization in high magnetic field. J. Polym. Sci. Part A Polym. Chem., 2004, 42(22), 5678-5686.

[21] Harivardhan, L.; Rayasa, R.; Murthy R. Influence of polymerization technique and experimental variables on the particle properties and release kinetics of methotrexate from poly(butylcyanoacrylate) nanoparticles. Acta Pharm., 2004, 54, 103-108.

[22] Takakura, Y.; Matsumoto, S.; Hashida, M.; Sezaki, H. Enhanced lymphatic delivery of mitomycin $\mathrm{C}$ conjugated with dextran. Cancer Res., 1984, 44, 2505-2510. 
[23] Voorn, Dirk-Jan; Ming, W.; Alex, M.; van Herk. Diffusioncontrolled reactive coupling at polymer-polymer interfaces. Macromolecules, 2005, 38, 3643-3646.
[24] Masuhiro, Y.; Yoshifumi, T., Eds. In Magneto-science, magnetic Field Effects on Materials: Fundamentals and Applications, Springer Series in Materials Science, Kodnasha Scientific Ltd., Tokya, Japan, 2006; vol. 89.

(C) Nita et al.; Licensee Bentham Open.

This is an open access article licensed under the terms of the Creative Commons Attribution Non-Commercial License (http://creativecommons.org/licenses/by-nc/3.0/) which permits unrestricted, non-commercial use, distribution and reproduction in any medium, provided the work is properly cited. 